\title{
CAMINHOS DE INVESTIGAÇÃO COM CRIANÇAS PEQUENAS: ROMPENDO FRONTEIRAS ${ }^{1}$
}

Elaine de Paula ${ }^{2}$

\section{Resumo}

O texto que segue tem como origem uma investigação de mestrado, em que a motivação central foi procurar compreender as práticas educativas desenvolvidas em uma instituição de educação infantil pública do município de Florianópolis. Foram sujeitos da pesquisa um grupo de 20 crianças com idade entre 3 a 4 anos. A análise recorta dessas práticas as relações estabelecidas entre adultos e crianças no interior da instituição, especialmente aquelas situações consideradas pelos adultos como de “transgressão" por parte das crianças. Destaco aqui o percurso metodológico do trabalho com o objetivo de registrar as possibilidades de pesquisa com as crianças ressaltando sua condição de sujeitos sociais plenos e, portanto, interlocutores capazes para dizerem de si mesmas. .As relações entre pares revelaram um certo grau de cumplicidade da formulação de estratégias pelas quais "burlavam" algumas das regras impostas pelos adultos. Tais observações constituem um alerta e uma orientação para aqueles que pretendem construir uma pedagogia que transite da regulação para a emancipação dos sujeitos.

Palavras-chave: Educação Infantil; metodologias de pesquisa; transgressão.

\footnotetext{
${ }^{1}$ Texto escrito tendo como referência a dissertação de mestrado da própria autora, intitulada "Deu, já brincamos demais!" As vozes das crianças diante da lógica dos adultos na creche: transgressão ou disciplina? Defendida no Centro de Educação da Universidade Federal de Santa Catarina/UFSC.

${ }^{2}$ Doutoranda em Educação pela Universidade Federal de Santa Catarina. Linha de Pesquisa: Ensino e Formação de educadores. 2010.
}

Revista Reflexão e Ação, Santa Cruz do Sul, v.18, n2, p.113-135, jul./dez. 2010 


\section{Introdução}

A porta da verdade estava aberta, mas só deixava passar meia pessoa de cada vez (ANDRADE, 2002). ${ }^{3}$

Assim não era possível atingir toda a verdade, porque a meia pessoa que entrava só trazia o perfil de meia verdade. E sua segunda metade voltava igualmente com meio perfil. $\mathrm{E}$ os meios perfis não coincidiam (ANDRADE, 2002).

Este texto pretende suscitar reflexões a partir do mergulho empreendido por ocasião de um trabalho de investigação, especialmente reflexões em torno do trabalho de campo, o qual contou com a participação de um grupo de 20 crianças com idades entre três e quatro anos que frequentavam uma instituição pública de educação infantil municipal na região sul do Brasil (Florianópolis - Santa Catarina). Fazer pesquisa envolvendo crianças na faixa etária de 0 a 6 anos tem sido um dos desafios postos para a área da educação infantil nos dias atuais. Se investigar 'sobre' as crianças já gerava dúvidas e inquietações no pesquisador, o que dizer da proposta de fazer pesquisa 'com' as crianças, reafirmando o propósito de considerá-las como interlocutoras competentes para dizerem de si mesmas obrigando-nos a levar em conta também os pontos de vista delas. Partilhar nossos objetivos e intenções com elas, bem como incorporar em nosso plano de trabalho outros direitos, desejos e indicações. Algo que até então era unilateral.

Como a perspectiva teórica que serviu de referência para o trabalho propugna que as crianças são capazes de falar por si e de apontar desejos e direções que melhor atendam aos seus interesses, colocou-se como um dos desafios para a pesquisa ouvir as crianças. Tentar perceber o que expressam e como se expressam sobre aquilo que lhes é consentido ou negado na creche, foi o grande desafio metodológico no caminho de

\footnotetext{
${ }^{3}$ Poema de Carlos Drummond de Andrade, 'Verdade'. Ao longo do texto aparecerão outras estrofes que integram esse mesmo poema.
}

Revista Reflexão e Ação, Santa Cruz do Sul, v.18, n2, p.113-135, jul./dez. 2010 
tentar compreender como se constituía aquele cotidiano institucional (espaço físico, pessoas adultas, outras crianças). A principal expectativa era conseguir reconhecer ali, na prática cotidiana, indicadores da capacidade de agência das crianças, bem como situar em que momentos isso se revelava.

\section{Adultos e crianças: os sobretons dessa relação}

Arrebentaram a porta. Derrubaram a porta. Chegaram ao lugar luminoso onde a verdade esplendia seus fogos. Era dividida em metades diferentes uma da outra (ANDRADE, 2002).

Começo com a observação do cotidiano das crianças na creche, procurando conhecê-las a partir de suas formas de tecer relações sociais, tanto com seus pares como com os adultos. A intenção era marcar, especialmente, aquelas situações consideradas pelos adultos como sendo de transgressão por parte das crianças. A opção por esses momentos foi por entender que, pelo fato de expressarem conflitos intergeracionais, tais momentos poderiam revelar questões importantes nas relações estabelecidas no interior da creche. Procurei também confrontar essas relações com aquelas estabelecidas entre as próprias crianças, bem como analisar essas últimas na tentativa de capturar a lógica delas e sua maneira de dar sentido ao que vivenciavam. Para tanto, procurei utilizar alguns procedimentos inspirados nos estudos qualitativos de cunho etnográfico ${ }^{4}$.

Acompanhando a rotina da instituição: o lanche; os momentos de higiene; as atividades dirigidas; as atividades no espaço externo à sala de referência (parque); o almoço; o sono e até os passeios (para fora da creche), fui desvelando um mundo marcado pela diversidade, pela cumplicidade entre as próprias crianças (pares) e pela

\footnotetext{
${ }^{4}$ Segundo Geertz (1989), etnografia é uma prática realizada na antropologia e consiste numa descrição densa do trabalho em campo, o que importa numa busca profunda e contextualizada dos significados. Portanto, penso que nós, da educação, o que fazemos é estudos que seguem as orientações da prática etnográfica .Ver também outros autores: André (1995); Graue e Walsh (2003).
} 
construção de estratégias de resistência, principalmente quando as crianças se encontravam afastadas dos adultos. Fui observando, também, o mundo dos adultos e percebendo certa tendência de homogeneização das práticas educativas quando interagiam com as crianças. Embora sejam mundos que se interpenetram, as crianças e os adultos produzem significados e sentidos, muitas vezes distintos, que, ao se entrecruzarem, produzem tanto oposições, acomodações, como conflitos, que geram tensões para ambos os lados.

Durante os dias na creche, fui percebendo as crianças submersas numa sucessão de atividades, seja com seus pares, seja com crianças de outras idades ou com os adultos. Quase sempre faziam o que era proposto e previsto, mas, às vezes, reinventavam jeitos de fazer, especialmente naquilo que nem sempre lhes era permitido naqueles espaços e tempos, rompendo obstáculos que se opunham aos seus interesses.

A aceitação das crianças da minha posição como parceira nas suas brincadeiras, nos seus contos, nas suas 'coisas sérias', permitiu imiscuir-me em seus mundos, resgatando minha dimensão da infância adormecida sob o manto da seriedade, da produtividade e até da sisudez que muitas vezes caracteriza os adultos. Tentei acatar o que relata Corsaro (2005) quando de uma experiência de entrada em campo, a melhor maneira para tornar-me parte dos universos das crianças era não agir como um adulto típico.

Embora não pretendesse me livrar da condição de adulta, entendi também ser preciso libertar-me das amarras adultocêntricas e das dimensões utilitaristas que amiúde atribuímos a todos os atos que realizamos. Assim, estar com as crianças foi esforçar-me para transcender o olhar daquilo que estava acostumada a ver, perceber a incompletude de cada ser, de cada grupo humano, de cada cultura. 
Nesta direção, senti-me reforçada na certeza de que a abordagem metodológica mais adequada para a pesquisa fosse mesmo uma abordagem qualitativa, uma vez que buscava compreender os fatos em sua dimensão de totalidade não aditiva, mas sim significativa pelas relações que estabelecem entre as partes e o todo. Foi esta percepção que implicou tomar como referência os estudos do tipo etnográfico com o intuito de observar de forma sistemática as crianças e os adultos, principalmente naqueles momentos em que se colocavam regras explícitas de controle e organização. Na busca de captar a dinâmica do cotidiano, acompanhei muitas vezes a chegada das crianças à creche, bem como os momentos de saída. Apoiada também no conceito de observação participante que, segundo Cohn (2005), consiste em uma interação direta e contínua de quem pesquisa com quem é pesquisado, registrei a ação das regras explícitas (por meio de um mapeamento) e as relações estabelecidas entre adultos e crianças.

As alternativas para apreender o que as crianças tinham a dizer delinearam-se de diversas maneiras. Inicialmente utilizei-me de um caderno para anotar os acontecimentos no terreno. Tentava registrar tudo o que acontecia. Claro que nem sempre isso era possível, pois as crianças insistiam em também fazer anotações no meu caderno e o revezavam comigo. Em um primeiro momento, o foco foi a observação das relações entre os adultos e as crianças: como as crianças reagiam ao que estava sendo proposto pelos adultos e como estes construíam as regras implícitas e explícitas nas suas condutas? Apenas em um segundo momento passei a observar as relações das crianças com seus pares na tentativa de apreender também o sentido que elas atribuíam às coisas que estavam a sua volta. Lembrando que parti do princípio segundo o qual as crianças são competentes para dizer de si mesmas e para apontar desejos e direções que melhor atendam aos seus interesses, tornava-se imperioso perceber em que momentos e em que espaços isso, de fato, se evidenciava.

Revista Reflexão e Ação, Santa Cruz do Sul, v.18, n2, p.113-135, jul./dez. 2010 
Tentei estabelecer uma relação com os envolvidos na pesquisa por meio de uma aproximação que possibilitasse trocar impressões e registrar aspectos relevantes acerca do objeto investigado. Tal estratégia, que envolveu observação, partilha de conhecimentos e participação em algumas situações nos espaços utilizados pelas crianças e professores, facilitou bastante o estabelecimento de um vínculo de respeito, confiança e afetividade. É importante destacar que foi necessário assumir uma nova atitude epistemológica ${ }^{5}$ possível de ser traduzida em um olhar e em uma escuta sensíveis a interpretar, compreender e atribuir significados às ações das crianças e dos adultos. Da mesma forma considero importante destacar que a investigação retratou minha preocupação em focalizar as crianças também como sujeitos da pesquisa. $\mathrm{O}$ pressuposto aqui é que a relação pesquisadora-pesquisados não se dá de maneira unilateral, mas sim pelo estabelecimento de um diálogo e pelo exercício da alteridade, procedimento imprescindível ao respeito à cidadania de que cada um - criança ou adulto - é portador. Conforme Souza (2005, p.04),

\begin{abstract}
assumir o dialogismo e a alteridade como marcas das relações estabelecidas no contexto da pesquisa significa ir ao encontro do outro e compartilhar experiências, conhecimentos e valores que se alteram mutuamente. $\mathrm{O}$ outro, no caso aqui a criança, não é apenas um objeto a ser pesquisado ou um informante de dados a serem analisados, mas é um sujeito cuja palavra confronta-se com a do pesquisador, exigindo um posicionamento, uma resposta.
\end{abstract}

A imersão que realizei no espaço das crianças revelou-se um universo, muitas vezes, inusitado e imprevisível. Um universo também construído pelas crianças, pois muitas vezes rompiam com as determinações do cotidiano, obrigando-me, assim, a um repensar a respeito das explicações sociológicas tradicionais (conferir Durkheim), de uma socialização unidirecional de cima para baixo, segundo as quais a sociedade

\footnotetext{
${ }^{5}$ Ferreira (2002), atitude epistemológica significa uma escuta sensível por parte do pesquisador daquilo que as crianças dizem, procurando captar a densidade de sentidos do que está envolvido na situação
} 
determina a lógica de existência das pessoas, e suas ações são praticamente soterradas sob a estrutura social.

Nesse movimento pude perceber que, com a saída de cena dos adultos, as crianças tendiam a ampliar os espaços de clandestinidade nos quais, muitas vezes, invertiam regras e ordens predeterminadas, criando estratégias em favor de interesses e direitos que julgavam ter. Antes de adentrarmos em exemplos das falas das crianças, apresentados neste texto, vale a pena ressaltar que, no diário de campo, procurei representá-las de forma semelhante àquela que elas se expressaram durante as sessões de pesquisa. Reproduzi acréscimos, omissões, alterações tônicas, flexão verbal diferenciada, acentuações, etc. que representavam a maneira como elas falavam naquele local e naquele momento. Vejamos, então, um exemplo das estratégias de negociação e contorno de dificuldades expresso pelas crianças:

As crianças estavam brincando nas mesas. Relo foi até sua mochila e pegou
um saquinho de bala. Power Rangers lhe pediu uma, como Relo lhe negou,
automaticamente o denunciou à professora, esta por sua vez pediu que as
balas fossem guardadas. Relo então falou baixinho para o amigo: não vou
guardar porque foi minha avó que me deu. Ao passo que Power Rangers
respondeu: Ah é, vou falar para a professora de novo. Relo então
rapidamente falou: Está bom seu 'zolhudo', eu te dou uma, só uma, porque
da outra vez tu comesse quase tudo. Power Rangers aceitou a bala e Relo
pôde comer o restante, clandestinamente (Registro em diário de campo).

Diante da tentativa de descortinar os universos infantis a partir de um olhar e de uma escuta atenta, sobre o que elas fazem e dizem, a leitura de Kramer (2002) levou-me a acrescentar alguns questionamentos: como ir até onde as crianças estão e ser realmente aceita por elas? Qual a maneira mais adequada para entender como as crianças agem, como se relacionam? Se, de fato, produzem cultura, como o fazem? Qual a necessidade de descentralizar o olhar do que estamos acostumados a ver? Por que ouvir o que as crianças falam? Por que olhar para a direção que elas nos apontam? Enfim, quais as razões para não enxergá-las apenas como meros figurantes? 
Aproximar-se de novas maneiras de investigação com as crianças e considerar seus pontos de vista requer a abertura de novas perspectivas e possibilidades de ação com elas. Interpretar suas falas para além do verbal não é tarefa das mais fáceis, pois exige, no mínimo, um olhar mais afinado e sensível. Lancei-me nesse desafio para tentar colocar em evidência os pontos de vistas das crianças e evitar a naturalização que nega ou dissimula as manifestações delas por considerá-las sem importância. Fiz com o pressuposto de que as crianças, ao se diferenciarem dos adultos, fazem emergir

contínuas e novas situações que precisam ser discutidas e pensadas, tanto para a reorganização do cotidiano como para a compreensão da forma como sentem, imaginam e pensam o mundo em que vivem diariamente.

Transgressões, regras e percursos: situações que se revelam nas ações e nas vozes das crianças

Chegou-se a discutir qual a metade mais bela. Nenhuma das duas era totalmente bela (ANDRADE, 2002).

Tive uma preocupação inicial em relação ao nome das crianças. Manter os verdadeiros ou atribuir-lhes denominações fictícias? Por uma questão ética é comum propor a adoção de nomes fictícios para as crianças, mesmo que não se tenha a intenção, como foi meu caso, de fazer um trabalho denunciatório que possa colocá-las em risco. De qualquer forma, optei por alterar seus nomes quando fosse transcrever seus pontos de vista. Isso gerou meu primeiro impasse. Ora, se parto de uma concepção teórica que concebe a criança como ator social e como sujeito da pesquisa, não seria condizente com meus referenciais excluí-las desta decisão. Na verdade aqui existiam duas decisões a serem tomadas: uma em relação à necessidade de usar um nome fictício e outra em relação a qual nome usar.

Admito que nem todas as questões que possam causar impacto nas relações sociais podem ser discutidas em toda a complexidade que possuem, com crianças de 
qualquer faixa etária. Mas, para mim, o importante aqui era, mais uma vez, não naturalizar as restrições que impomos às crianças o que acaba por não mobilizar qualquer esforço para ampliar as formas de diálogo que venham a permitir uma ampliação cada vez mais envolvente da participação das crianças nas tomadas de decisão que digam respeito à vida delas. Devemos, no mínimo, não esconder de nós mesmos a existência de tais restrições e a necessidade de serem permanentemente revistas e criticadas.

Entendi que, através da segunda questão (qual nome escolher?), poderia inserir um processo pelo qual as crianças pudessem perceber, pelo menos em determinada medida, o teor das questões éticas e sociais que estavam envolvidas na decisão de trabalhar com nomes fictícios e não com seus verdadeiros nomes.

Para tanto, inspirei-me em uma experiência descrita no texto $\mathrm{O}$ que falam de Escola e Saber as crianças da Área Rural? Um desafio da Pesquisa no Campo (Leite, 1996), na qual a autora discorre sobre a opção, por ocasião de sua pesquisa de campo, de substituir os nomes verdadeiros das crianças e pedir que elas mesmas escolhessem os nomes que gostariam que aparecessem no texto. A pesquisa de Leite (1996), contudo, foi realizada com crianças entre seis e quatorze anos de idade. Servia-me como referência, mas, para os sujeitos de três a quatro anos com os quais interagia, o que fazer?

Precisava encontrar uma maneira significativa para que as crianças participassem da criação de seus nomes. Resolvi, então, criar uma história a partir do cruzamento de três livros de literatura infantil ${ }^{6}$, à qual acabei chamando: Nome de Brincadeira. $\mathrm{O}$ enredo da história era novo, mas as imagens foram retiradas dos três livros, assim as crianças puderam manusear as figuras e fazer comentários de maneira

\footnotetext{
${ }^{6}$ Pausewang (2000); Livia e Orlov (2003); Padilha (2006).
} 
simultânea à invenção dos nomes. O trabalho foi desenvolvido com quatro grupos, numa média de três a seis crianças por grupo. A todos os grupos relembrei o que estava fazendo na creche e o que escrevia no caderno freqüentemente.

Perguntei, então, às crianças quais nomes gostariam que fossem consignados a elas na pesquisa. Diziam elas: deixa eu escrevo no teu caderninho. Alguns escolheram personagens de séries da televisão como: Powers Rangers, Emília, Batmam; outros, de contos de fada: Cinderela, Branca de Neve, Emília; houve opção por nomes ou apelidos de amigos ou familiares: Gabriel, Aline, Tuana, Stefani, Duda; houve os que não concordaram em trocar seus nomes, e por fim, alguns nomes foram inusitados, como: Tarandelo, Raudio e Relo. Esses últimos nomes julguei que seriam esquecidos rapidamente, porém, quando fomos para a sala, as crianças foram as primeiras a anunciá-los para as demais que lá estavam.

Para uma outra atividade que me interessava desenvolver com as crianças na busca de compreender o que as crianças achavam da vida que levavam ali na creche, desenvolvi uma estratégia semelhante à utilizada para a brincadeira dos nomes. Assim como na construção dos nomes, também interagi com grupos pequenos de crianças, numa média de três a cinco por grupo e num espaço separado das demais. A proposta foi iniciar com a narração da seguinte história: Do que é que você gosta?, de (Gerard Gréverand, 2001). Deitadas ou sentadas no parque, as crianças ouviam a história, e sobre ela opinavam e desenhavam.

Ah!, sabe que eu gosto muito de brincar de Barbie girl? Tu também né, Emília? Emília apenas consentiu com a cabeça. Duda continuou falando: Eu tenho Barbie girl na minha casa. Só que minha mãe não deixa trazer para a creche, porque senão as outras crianças vão pegar, prefiro não trazer. Raudio, olhando a Duda, mexeu a cabeça negativamente e lhe disse: Eu trago o meu carrinho, está lá na minha mochila. Tarandelo interveio em tom intimidador e, esticando o pescoço e olhando enviesado para Raudio, falou: Então pega para nós brincar aqui fora. Raudio, novamente mexendo a cabeça negativamente, falou: Tu não sabe que nós estamos fazendo outra coisa, não? Tarandelo não respondeu e falou do que gostava de fazer: Eu gosto mais de brincar de bola e de parque. Enquanto falava, Tarandelo desenhava. Raudio disse que gostava de brincar de pipa e também 
desenhou. Perguntei a Emília, que até então não tinha falado, porém estava todo tempo desenhando com hidrocor, o que ela gostava de fazer. Emília me olhou séria, depois estralando a língua e mexendo a cabeça, parecendo estar meio impaciente, respondeu: Tem um montão de coisa que eu gosto de faze, né ? Eu gosto de brincar com as amigas. Não estás vendo? E apontou para seu desenho (Registro em diário de campo).

As crianças algumas vezes paravam de desenhar e falar e dirigiam-se aos brinquedos do parque para mostrar como gostavam de brincar.

Quando novamente nos reunimos, criei uma história, sem imagens, falando de coisas que as crianças não podiam fazer. Interessante naquele momento foi o convite do Tarandelo para que fôssemos para dentro dos canos de cimento que existem no parque, para que pudéssemos ficar 'escondidinhos', ou como disse Duda: É, tem que falar baixinho para ninguém escutar. Perguntei por que e Duda arregalou os olhos dizendome: Senão elas vão escutar. Talvez referindo-se a dois adultos que passavam próximos a nós.

Tentei ainda fazer outras questões sobre isso, mas as crianças começaram a discutir as cores das canetas de hidrocor. Depois Tarandelo retomou a conversa. Sabia que não pode brincar quando faz bagunça? Para representar a bagunça ele fez um desenho com várias voltas. Raudio, que até então olhava sério para Tarandelo, deu de ombros e falou: Também quando vai dormir não pode brincar, tem que fechar o olho. Em seguida convidei as crianças para irem à sala, já que as demais estavam vindo para o parque e eu gostaria de continuar conversando com eles. Ao chegar à sala Duda foi logo falando: Sabe que não pode levar boneca para o parque? Emília retrucou: Ahhh..., Duda, tem vez que pode, sim. Duda não respondeu. Raudio também falou que não podia mexer nas caixas com brinquedos sem falar para a professora, porém olhou para Tarandelo e falou: Vão pegar? Tarandelo rapidamente consentiu. Ambos pegaram a caixa, que parecia estar muito pesada pela expressão que fizeram. Dentro havia óculos, bolsas e vários objetos pequenos. Tarandelo, após colocar os óculos escuros, pediu-me 
para tirar uma foto sua na rua. Duda interveio e, apontando e balançando o dedo indicador para Tarandelo, falou: Tu não sabe que não pode ir para rua com esse, óculos? É de sol, respondeu Tarandelo, e foi para rua, mas apenas para que tirássemos uma foto sua (Registro em diário de campo).

Os desenhos das crianças, em geral, permitiam entrever muito de sua forma de ver o mundo, de suas emoções, mas chamou-me a atenção que, naquilo que consegui interpretar, as coisas agradáveis e permitidas de se fazer na creche se apresentaram em número bem maior do que as coisas que não podiam ser feitas.

Coerente com a conviç̧ão, muitas vezes reiterada, de que as crianças têm condições de interpretar as coisas que estão a sua volta, bem como condições de instituir novas maneiras de agir, mantive a proposta de envolver todas elas na dinâmica e dei continuidade, num outro dia, com outro grupo de quatro crianças.

Parti novamente da mesma história do grupo anterior e utilizei os mesmos materiais: folhas de cartolina, hidrocor, máquina fotográfica. Acrescentei nesse dia um gravador. Assim, as crianças puderam escutar suas vozes, o que causou um grande contentamento e espanto ao ouvirem, ao final, o que haviam falado.

Com esse grupo, utilizei outra dinâmica para que as crianças pudessem se expressar. Apesar de ter iniciado também com a mesma história, nesse grupo, diferente do grupo anterior, as crianças expressaram com mais ênfase o que não podiam fazer na creche. Em seguida fizemos a representação de um dia de creche, em que os papéis e personagens foram escolhidos pelas próprias crianças. Mais uma vez, reitero que as crianças são capazes de se expressar utilizando outras linguagens, de serem autoras de suas ações e de falar sobre suas infâncias.

Para continuar conversando sobre o cotidiano na creche e sobre as relações estabelecidas com os adultos, propus que brincássemos de casinha no parque. 
Rapidamente as crianças aceitaram e Stefani determinou os papéis de cada um. Ela seria a mamãe, Vilson, o papai e Oscar e eu, os filhos. Batmam não aceitou participar da dramatização. Um outro personagem foi acrescentado à brincadeira, uma boneca, que seria o bebê.

Além de criar estratégias para que as crianças se expressem verbalmente ou através de outras formas de expressão, é necessário organizar espaços para que isso aconteça. Quando nos dispomos a escutá-las, percebemos o quanto elas têm a dizer daquele lugar em que tanto elas quanto os adultos passam grande parte do dia e das suas vidas. Percebemos que as crianças conseguem relativizar as regras entre os pares; ainda que constrangidas pela estrutura social, elas conseguem ouvir e fazer-se ouvir e até alterar suas ações, mesmo no confronto de opiniões.

As crianças tanto dizem o que gostam de fazer como também o que não gostam, então, por que mesmo assim continuamos a insistir em fazer o que elas não querem? Será que estamos realmente prestando atenção ao que nos falam?

Perceber a atuação das crianças nas relações sociais e no interior dos espaços em que circulam diariamente é compreender que elas produzem sentidos para as experiências que vivenciam tomando como referência o sistema simbólico que as envolve. Também partilham significados que, embora diferentes dos adultos, não significa que sejam inferiores. Portanto, continuo reiterando minha convicção de que as crianças têm condições de instituir novas maneiras de agir sobre a realidade.

Para continuar explorando possibilidades de perceber a expressão das crianças utilizei, certa vez, fantoches para dialogar com elas. O cenário foi criado utilizando algumas miniaturas: carrinhos, loucinhas, bonecas, animais, avião. Mais uma vez constatei a maneira diferenciada de expressão das crianças e de tradução daquilo que vivenciam. 
Como um dos pontos delicados na creche é o momento do sono, fui criando com o fantoche uma história em que ele falava sobre o sono na creche. E por meio da história as crianças faziam relação com aquilo que experimentavam, mas não apenas com coisas imediatas, também com aquelas ocorridas há algum tempo. As crianças demonstraram um complexo de visão da realidade, expressando-se tanto por meio do desenho, como através da oralidade. Vejamos este diálogo originado de uma história sobre o sono por mim contada:

Eu gosto de dormir, diz Tuana. Não gosta, não gosta, tu até chora, retruca Emília. Na minha casa que eu durmo, na creche que eu não durmo, diz novamente Tuana. Ela dorme, mas não gosta, diz Gabi. Deixa Tuana, faz assim oh! Fica só com um (olho) fechado na creche, nem eu durmo, só fico acordado, fala por último Raudio (Registro em diário de campo).

O que expressam as crianças fez-me refletir sobre se, de fato, estamos considerando seu ponto de vista no planejamento do cotidiano da creche. Em que medida suas reivindicações ou opiniões são atendidas? Se a estrutura física e os recursos humanos são insuficientes nos espaços institucionalizados, o que precisa ser feito? Será que são as crianças que devem arcar com as dificuldades existentes?

Com algumas crianças, a despeito do interesse demonstrado ao escutar a história, não houve manifestação do desejo de desenhar ou falar sobre aquilo que estava sendo proposto. Resolvi, então, experimentar uma outra dinâmica: utilizar a lente da máquina fotográfica para estimular a conversa sobre o que gostavam e o que podiam fazer na creche ${ }^{7}$. De acordo com Guran (2000), uma das potencialidades da fotografia é destacar um aspecto particular da realidade que se encontra diluído num vasto campo de visão, explicitando assim a singularidade e a transcendência de uma cena. Não era minha intenção trabalhar as fotografias em profundidade, ou seja, escolher melhor ângulo para fotografar, cuidar da posição do sol, fixar a máquina para que as imagens

\footnotetext{
${ }^{7}$ Havia lido em um outro trabalho (Fernandes,1998) que a pesquisadora utilizou o mesmo recurso e que havia dado certo. Não obstante meus sujeitos fossem de outra faixa etária, resolvi experimentar.
} 
não saíssem tremidas, dentre outros cuidados que aquilo que é considerado uma fotografia de qualidade exige, até porque, tanto eu como as crianças éramos amadores. Meu intuito foi perceber o que as crianças iriam destacar, assim como incluir outras maneiras de sua participação na pesquisa e compreender o contexto da creche pela perspectiva de seus olhares.

Quando retornei com as fotos já impressas, nos sentamos em círculo na sala e distribuí as fotos para que todos tivessem acesso à totalidade de fotografias tiradas, já que, apesar de iniciar com um grupo específico de crianças, a máquina fotográfica foi dada também para outros grupos em momentos diferentes.

Inicialmente senti-me frustrada porque as crianças não identificaram as fotos que haviam feito. Também suas intenções, ao verem as fotos, já não eram mais as que haviam verbalizado quando as fizeram e o desejo agora era pelas fotos em que eles apareciam, não por aquelas que haviam tirado.

Entendi com essa avaliação das crianças, e por meio dos registros que fiz na ocasião das fotos, que o que foi significativo para elas naquele momento e, agora, também para mim, foi o uso afetivo que elas fizeram daquele instrumento, ou seja, das emoções que elas viveram ao manusear a máquina (a emoção de fotografar e ver o resultado na câmara digital instantaneamente), da euforia com o fato de chamar os amigos para juntos ver e rirem das 'caras e bocas' que apareciam nas imagens. Permitir às crianças o uso da máquina fotográfica proporcionou a elas, antes de tudo, a partilha de vivências lúdicas com seus amigos e a satisfação de utilizar um instrumento que, geralmente, integra o universo dos adultos.

O momento de circulação das fotos foi eivado de significados pela discussão que proporcionou entre as crianças. Como anteriormente destaquei, o interesse naquele momento foi pelas imagens em que elas apareciam, o que acabou trazendo alguns 
problemas, uma vez que havia mais de uma criança em cada foto. O impasse se estabeleceu para ver com quem ficaria a foto. A intervenção dos adultos deu-se em alguns momentos, porém em outros as próprias crianças negociaram com quem ficariam as fotos, utilizando razões bem convincentes, como a que Xuxa usou para convencer Aline: Tu não pode ficar oh, teu olho nem está na foto! ${ }^{8}$ E Aline aceitou o argumento.

Ao final, com as fotos já escolhidas, falei às crianças que algumas daquelas fotos talvez integrassem o texto do meu 'caderninho', assim como outras que eu já havia feito. Falei-lhes também da autorização dada por suas famílias para que eu pudesse utilizar as fotos e mostrei-lhes o documento assinado pelos pais. Mostrei às crianças um documento similar àquele outro, porém com um pedido para que elas, e não os seus pais, me autorizassem a utilizar as imagens que registramos. Enfim, solicitei a autorização das crianças para a publicação das fotos em minha pesquisa.

Esse procedimento pode parecer ao leitor evasivo, por considerá-lo destituído de significado para as crianças, porém, para além da cartorização ou burocratização de um ato, no que tange à assinatura ou não de um documento, a magnitude daquele momento para as crianças deu-se pela seriedade com que fizeram sua simbólica assinatura, insistindo para que eu apontasse onde estavam seus nomes. Aqui o importante é o fator pedagógico no que diz respeito ao direito de expressar seu acordo ou desacordo em situações que as envolvem diretamente.

Ainda com a intenção de dar visibilidade e compreender as diferentes representações sociais das crianças a partir delas mesmas, continuei a reinventar procedimentos que pudessem captar suas interpretações sobre a realidade que as cerca,

\footnotetext{
${ }^{8} \mathrm{Na}$ foto tirada por uma das crianças, os olhos de Aline não aparecem. Esse foi o argumento utilizado por Xuxa para ficar com a fotografia.
} 
suas relações inter ou intrageracional, ou ainda com os espaços físicos/temporais do cotidiano institucional. Dessa forma, procurei utilizar as fotografias já impressas para que as crianças, individualmente, fizessem a leitura das experiências naquele espaço. Minha proposta foi de conversar apenas com algumas crianças em razão do tempo escasso que eu tinha para terminar a pesquisa de campo, mas tive o cuidado de escolher não apenas aquelas que tinham a oralidade mais presente, mas também as que pouco se expressavam verbalmente em sala. Minha surpresa foi grande ao perceber que as duas crianças que convidei para falar sobre as fotos, as quais na sala pouco falavam com as demais, nomeavam os amigos presentes nas fotos, falavam sobre as brincadeiras captadas pelo instantâneo da máquina fotográfica, falavam de suas preferências, enfim, expressavam modos diferentes daqueles de quando estavam em grande grupo.

As considerações das crianças ao manusearem as fotografias revelou que as imagens podem ser instrumentos auxiliares de análise e de reorganização das práticas educativas, à medida que se faça uso delas para compreender o que as crianças estão dizendo e querendo. As informações levantadas podem ajudar os adultos a criarem espaços mais motivadores para as crianças e confirmar nossa perspectiva de que as crianças são competentes para expressar o que desejam no cotidiano em que estão imersas.

Em uma das fotos Raudio falou: Olha aqui, nós se escondendo da Sandra. A Maria disse para nós se esconder e disse que brincar depois de dormir e todo mundo dormiu... eu não. Quando viu a foto de Batmam (uma das crianças do grupo) de pé no balanço se assustou: Oh! esse daqui é bem louco, olha lá onde ele foi, foi bem para lá na pedra. Ele pode bater e voar "pitfffff", bater e se machucar. Quando perguntei como ele achava que Batmam deveria brincar, respondeu-me: Sentado, devagarinho porque senão bate nos bebês e daí machuca. Eu brinco sentado assim... não consigo ficar em pé... mas eu queria (Registro em diário de campo).

Esse excerto também demonstra que as crianças, apesar de constrangidas pela estrutura e reproduzirem os condicionantes de uma ordem social, ensaiam uma leitura 
diferente do que está determinado e deixam escapar o quanto gostariam de fazer de outro jeito.

Quando viu um de seus amigos subindo na árvore falou: Oh! Ele está subindo aqui na árvore, pode subi, porque a árvore não é pequeninha, se ela fosse pequininha iria quebrar e ele ia cair. Essa arvore é grande (Registro em diário de campo).

Os destaques que Raudio foi fazendo das fotografias revelam aspectos importantes das brincadeiras, das relações estabelecidas com outras crianças e com os adultos, e daquilo que foi ou poderia ser significativamente vivido por elas, levantando aspectos que convidam a refletir sobre esse cotidiano. Dar visibilidade e relevar as interpretações das crianças pequenas pode ser um grande passo para incluí-las como partícipes, tanto da pesquisa quanto do contexto educativo.

Finalmente, sintetizando essa questão, ressalto que a autoavaliação, a autoanálise que as crianças realizaram por meio das fotos mostraram sua capacidade de distanciamento e discernimento ao avaliarem fatos e situações ausentes no tempo e no espaço, ainda que tornados presentes e vivos pelo registro fotográfico. No meu entender, essa dinâmica oferece valiosos subsídios ao desenvolvimento e avaliação de atividades pedagógicas.

\section{Considerações pretensamente finais... Mas, apenas para esse momento}

E carecia optar. Cada um optou conforme seu capricho, sua ilusão, sua miopia (ANDRADE, 2002).

Embora as ações mencionadas acima sejam ainda incipientes e possam suscitar reflexões mais abrangentes, não deixam de apontar um caminho na perspectiva de considerar as crianças também como agentes no campo da investigação e desencadear desafios, tanto teóricos como metodológicos, que nos levem a compreender o sentido que as crianças atribuem às coisas que as circundam, assim como as experiências que vivenciam no cotidiano da instituição, aspectos frequentemente considerados como sem importância.

Revista Reflexão e Ação, Santa Cruz do Sul, v.18, n2, p.113-135, jul./dez. 2010 
Ao partilharmos desses significados e legitimarmos as ações das crianças, enfatizamos sua competência social e seus modos de agir, entendendo que elas também têm direito a ver valorizados seus próprios interesses e não apenas os interesses que os adultos atribuem à vida delas.

Ao utilizar o campo de estudos da nova Sociologia da Infância, importa dizer que, embora este campo (ainda em formação) em sua gênese nos remeta mais a outras realidades, não deixa de representar uma orientação que potencializa os conhecimentos que vimos construindo na realidade brasileira. Temos, sem dúvida, ainda um longo caminho a percorrer quando falamos de pesquisas com as crianças pequenas. Várias pesquisas permitem perceber que elas ainda não foram totalmente constrangidas pelo controle das 'pessoas grandes' e pelas ordens instituídas na sociedade, podendo, portanto, ajudar-nos no processo de constituição do novo. Ao lançarem mão de estratégias criadas pelo seu repertório imaginativo, suas vivências, suas brincadeiras, seus questionamentos, suas desordens, enfim, suas culturas, as crianças tendem a desafiar a racionalidade dos adultos, tendem a transitar entre o instituído e o que pode ser transgredido, mostrando-nos formas de organizar o pensamento que a nós parecem estranhas e que, portanto, podem auxiliar na ampliação do nosso ponto de vista sobre a realidade.

É uma aposta, sem dúvida, mas que considero tão importante que não pode deixar de ser investigada em diversas frentes e de diferentes modos.

\section{PATHS OF INVESTIGATION WITH SMALL CHILDREN: BREAKING FRONTIERS}

\section{Abstract}


The following text has as its origin a Master's degree's investigation, where the central motivation was to attempt to comprehend educative practices developed in a Public Early Childhood Education Institution from Florianópolis city. A group of 20 children aged between 3 and 4 years-old were the research's subjects. The analysis highlights from those practices the relationships established between adults and children inside the institution, especially the situations which adults consider as "transgression" committed by children. I underline here the methodological course from this Study in order to register the possibilities of research with children, emphasizing their condition as full social subjects and, therefore, interlocutors capable of talking about their selves. The relationships among children (pairs) revealed a certain complicity degree in the formulation of strategies through which they "cheated" some of the rules imposed by adults. These observations constitute a alert and a orientation for those who intend to build a Pedagogy that changes from regulation to subjects' emancipation.

Key-words: Early Childhood Education; research methodologies; transgression.

\section{Referências}

ANDRADE, Carlos Drummont. Corpo. Rio de Janeiro: Record, 2002.

ABBAGNANO, Nicola. Dicionário de Filosofia (Tradução Alfredo Bosi). 2. ed. São Paulo: Martins Fontes, p. 841-844,1992.

ARIÈS, Philippe. A História Social da Criança e da Família. Rio de Janeiro: LTC, 1981.

ANDRÈ, Marli Eliza D. A. de. Etnografia da prática escolar. Campinas (SP): Papirus, 1995. (Série Prática Pedagógica)

AZANHA, José Mário Pires. Uma ideia de pesquisa educacional. São Paulo: Edusp/Fapesp, 1992. 
BRASIL, Lei de Diretrizes e Bases da Educação Nacional. Lei 9394/96, de 20 de Dezembro de 1996. Brasília/DF: MEC, 1996.

BRASIL. Lei $\mathbf{n}^{\mathbf{0}} \mathbf{1 0 . 6 3 9 / 2 0 0 3}$. Dispõe sobre a obrigatoriedade do ensino de História e Cultura Afro-Brasileira. Disponível em www.senado.gov.br (acesso em 10 de janeiro de 2008).

CAPUTO, Stela Guedes; PASSOS, Mailsa. Cultura e conhecimento em terreiros de candomblé - lendo e conversando com mãe Beata de Yemonjá. Currículo sem Fronteiras, v.7, n.2, pp.93-111, jul/dez 2007.

CHRISTENSEN, Pia; JAMES, Allison.(orgs) Investigação com crianças. Perspectivas e práticas. Escola Superior de Educação de Paula. Porto, Franssinetti, 2005.

COHN, C. (2005). Antropologia da Criança. Rio de Janeiro: Jorge Zahar.

CORSARO, Willian. Entrada no campo, aceitação e natureza da participação nos estudos etnográficos com crianças pequenas. Revista Educação \& Sociedade. CEDES ,Vol 26 - Mai./Ag. 2008. p.443 a 464.

CORSARO William A. Acção colectiva e agência nas culturas de pares de crianças pequenas. Department of Sociology, Indiana University, Bloomington USA, 1997 (mimeo).

CORSARO William A. A reprodução interpretativa no brincar ao "faz-de-conta" das crianças. Educação, Sociedade e Culturas, Porto, n.17, p.113 - 134, 2002.

DURKHEIM, Émile. Sociologia, educação e moral. Rés-editora: LTDA, Portugual,1984.

DELGADO, Ana C. \& MULLER, Fernanda. Sociologia da Infância: pesquisas com crianças. IN: Educação \& Sociedade: Revista de Ciência da Educação. Vol. 26, mai/ago. São Paulo: Cortez, 2005.

FARIA, Ana Lúcia; DEMARTINI, Zélia B. F; PRADO, Patrícia Dias (Orgs). Por uma cultura da infância: metodologias de pesquisa com crianças. Campinas/SP. Editora Associados, 2002.

FERREIRA, Maria Manuela Martinho. A Gente Aqui o que Gosta mais é de Brincar com os Outros Meninos: as crianças como actores sociais e a (re)organização social do grupo de pares no quotidiano de um Jardim de Infância. Porto, 2002. Dissertação (Doutoramento em Ciências da Educação). Faculdade de Psicologia e Ciências da Educação, Universidade do Porto.

FERREIRA, Maria Manuela Martinho. Do "avesso" do brincar ou... as relações entre pares, as rotinas da cultura infantil e a construção da(s) ordem(ens) social(ais) instituintes(s) das crianças no jardim-de-infância. In: SARMENTO, Manuel Jacinto \& CERISARA, Ana Beatriz. Crianças e miúdos: perspectivas sociopedagógicas da infância e educação. Edições ASA- Porto- Portugal 2004. 
FERNANDES, Florestan. As 'Trocinhas' do Bom Retiro. Folclore e Mudança Social na cidade de São Paulo. Vozes: Petrópolis, 1979 .

GEERTZ, Cliffort. A Interpretação das Culturas. São Paulo: Guanabara Koogan, 1989.

GREVERAND, G.; BARDOS, M. (2001). Do que é que você gosta? Rio de Janeiro: Salamandra.

GURAN, M. (2000). Fotografar para descobrir, fotografar para contar. Cadernos de Antropologia e Imagem. Rio de Janeiro, p. 155-165.

JAMES, Allison \& PROUT, Alan. Hierarquia, Fronteira e Agência: para uma perspectiva teórica sobre a infância. In: FERREIRA, Manuela e SARMENTO, M. J. (orgs.). Antropologia de Textos em Sociologia da Infância, Porto: ASA, 2004.

JAMES, Allison; JENCKES, Chris e PROUT, Alan. Teorizing childhood. Cambridge. Polity Press, 1998.

JAMES, Allison. Investigação com Crianças. Perspectivas e Práticas. Porto: Editora Porto, 2005, p. 243 - 260.

JENCKES, Chris. Constituindo a criança. Revista Educação, Sociedade e Culturas. Edições Afrontamento, LTDA: Porto, Portugal, n 17. p. 113-134, 2002.

KRAMER, Sônia, LEITE, Maria Isabel et al (orgs.) Infância e educação infantil. Campinas, SP: Papirus, 1999.

KRAMER, Sônia. Por entre as pedras: armas e sonho na escola. São Paulo: Ática, 1996.

KRAMER, Sônia. Autoria e autorização: questões éticas na pesquisa com crianças. In: Cadernos de Pesquisa. São Paulo, nº 116, p. 41-59, jul. 2002.

KRUPSKAYA, N. K. Acerca de la educación preescolar. Havana: Editorial Pueblo y Educación, 1979.

PAULA, Elaine de. "Deu, já brincamos demais!" As vozes das crianças diante da lógica dos adultos na creche: transgressão ou disciplina? Florianópolis, SC. Dissertação de Mestrado. Universidade Federal de Santa Catarina, 2007.

PAULA, E. Novos murmúrios sobre as metodologias de pesquisa com crianças pequenas: desafios e rupturas. Revista Contrapontos. Programa de Mestrado em Educação-Universidade do Vale do Itajaí-UNIVALI. V.8, p.131-146, 2008.

PAULA, E. Os muitos jeitos de ser e fazer das crianças: criação ou transgressão? Revista Eletrônica Zero-a-Seis. CED/UFSC. N N 14, 2006 .

PADILHA, F. G. (2006). Brinquedos falantes. São Paulo: Ática. 
PAUSEWANG, G. (2000). A escola dos meninos felizes. São Paulo: Loyola.

PINTO, Manuel; SARMENTO, Manuel J. As crianças. Contextos e identidades.Portugal, Centro de estudos da criança: editora Bezerra, 1997.

PINTO, Manuel. A televisão no quotidiano das crianças. Educação Sociedade \& Culturas, Porto, n.17, p.226-228, 2002. Resenha do livro: PINTO, Manuel. A televisão no quotidiano das crianças. Porto: Edições Afrontamento, 2000, 400 páginas. (Conceição Ventura e Rita Cabral).

PROUT, Alan. Reconsiderar a nova Sociologia da Infância: para um estudo multidisciplinar das crianças. Ciclo de Conferências em Sociologia da Infância. 2003/2004. IEC. Tradução: Helena Antunes. Braga/Portugal: 2004 (digitalizado).

PODDIÁKOV, N. Sobre o problema do desenvolvimento do pensamento nos preescolares. In DAVIDOV, V. e SHUARE, M. (orgs) - La Psicología Evolutiva y Pedagógica en la URSS (Antologia). Moscou: Editorial Progresso, 1987.

PISTRAK, P. Fundamentos da escola do trabalho. São Paulo: Expressão Popular, 2000.

QVORTRUP, Jeans. A infância na Europa: novo campo de pesquisa social. Centro de documentação e informação sobre a criança. Instituto de Estudos da Criança, Universidade do Minho. Tradução de Helena Antunes (mimeo).

ROBERTS, Helen. Ouvindo as Crianças: e escutando-as. In: CHRISTENSEN, Pia \& JAMES, Allison. Investigação com Crianças. Porto: Perspectivas e Práticas, 2005.

SARMENTO, Manuel J. \& PINTO, Manuel. As crianças e a Infância: definindo conceitos delimitando o campo. In: PINTO, Manuel \& SARMENTO, Manuel J. (coord.) As Crianças: Contextos e Identidades. Braga, Portugal: Centro de Estudos da Criança, 1997.

SARMENTO, Manuel J. \& PINTO, Manuel.(coord.). Saberes sobre as Crianças: para uma bibliografia sobre a infância e as crianças em Portugal. Braga, Portugal: Universidade do Minho, 1999.

SARMENTO, Manuel J.. A infância: paradigmas, correntes e perspectivas (mimeo). Florianópolis, 2002.

SARMENTO, Manuel Jacinto. Gerações e alteridade: interrogações a partir da sociologia da infância. In: Educação \& Sociedade, 2005, vol.26, n. 91.

SIROTA, Régine. Emergência de uma Sociologia da Infância: evolução do objeto e do olhar. Cadernos de Pesquisa, São Paulo, nº 112, pp.7-31, mar. 2001.

SILVA, Juliana Pereira da; BARBOSA, Silva Neli Falcão; KRAMER, Sônia. Questões teórico-metodológicas da pesquisa com crianças. Perspectiva, Florianópolis, v.23, n.01, p.41-64, jan./jul. 2005. 
Data de recebimento: $25 / 07 / 2010$

Data de aceite: 17/09/2010 